\title{
The computer as psychometrician
}

\author{
LAWRENCE G. SPACE \\ Department of Psychiatry, University of Rochester School of Medicine and Dentistry \\ Rochester, New York 14642
}

\begin{abstract}
The application of computers to the functions traditionally carried out by a psychometrician or psychologist is examined. Diagnosis, psychotherapy, interviewing, psychological testing, test interpretation, and report writing are reviewed. The advantages and disadvantages of using computers in assessment applications are discussed. Patient and professional acceptance of automated psychological services is reviewed, as well as the parameters to consider in the development of computerized interviewing and testing. Brief comments are made regarding suitable computer systems for these applications. It is argued that computers can provide a cost-effective enhancement to the delivery of mental health services.
\end{abstract}

Of concern to persons within and without the field of medicine has been the availability of effective economical health care. Within the last few years, efforts to improve access to adequate health care have taken several forms. These include improving the efficiency of medical education, increasing enrollment in medical schools, and applying technology to problems of diagnosis, treatment, and information handling. The inequality in the distribution of medical care is at least as marked in the field of psychiatry as in any other field of medicine (Coddington \& King, 1972). An increase in the psychological sophistication of the American public has increased the demand for psychiatric care. The demand for treatment exceeds the number of professional man-hours available. In response to this, and for other reasons as well, mental health professionals have shown an increased interest in partial hospitalization and outpatient treatment, aftercare programs, short-term hospitalization and/or treatment, preventive psychiatry, and the use of paraprofessionals. In addition, psychiatry, like other areas of medicine, has turned toward the use of computers to increase the efficiency of mental health care. However, compared with other areas of medicine, the search for the relationship among etiology, diagnosis, treatment, and prognosis is in its infant stages. Therefore, the application of computers to psychiatry is more than simply a matter of finding better ways to utilize an already existing body of knowledge.

In the field of psychiatry and psychology, computers have been used to (1) collect human and animal experimental data, (2) organize and mathematically analyze such data, (3) score/analyze verbally produced information (Gorham, Moseley, \& Holtzman, 1968; Harway \& Iker, 1969; Peck, Menaker, \& Veldman, 1966; Tucker \& Rosenberg, 1980), (4) recommend psychotropic medical

Requests for reprints should be sent to L. G. Space, Department of Psychiatry, University of Rochester School of Medicine, Rochester, New York 14642. and forecase elopement risk (Altman, Brown, \& Sletten, 1972; Sletten, Altman, Evenson, \& Cho, 1973), (5) model psychopathology (Colby, 1975), (6) provide management information services in mental health settings (Laska, Siegel, \& Bank, 1980), (7) provide patient therapy, (8) sort people into diagnostic categories, (9) interview for historical and other information, (10) produce narrative psychological reports, and (11) administer psychological tests.

The last four categories are those that most closely parallel the role of a psychometrician in a mental health setting, and thus they will be the focus of this paper. These functions, however, are part and parcel to the process of patient treatment, and a brief foray into the world of the computer and psychotherapy or patient treatment is of interest.

\section{THE COMPUTER AS THERAPIST}

Colby, Watt, and Gilbert (1966), Hogan (1971), and Lang (1969) were among the earliest to attempt to use an automated method to provide psychological treatment. Lang used a noncomputerized automated desensitization device and found it as effective as a line therapist in reducing focused phobic behavior. Colby et al. used a computer that accepted sentences, searched for key words, and then responded with a comment or question.

Pope and Gersten (1977) automated biofeedback, and Jennings (1978) used a computer in a counseling session (with a human being actually listening to the client and controlling the computer's responses) to compare with a human counselor. It was interesting to note that the human counsel rated higher on listening, understanding, acceptance of client views, and interest and respect for the client.

In an interesting application of electronic technology, Lang (1980) used a CRT as the feedback mechanism in biofeedback training; he is currently involved in developing assertiveness training via a computer. Cuthbert 
(1976) used a computer to give the relaxation training instructions of Benson (1975).

\section{THE COMPUTER AS DIAGNOSTICIAN}

The question of the computer as diagnostician goes back at least as far as Meehl (1954), who ignited the debate of clinical vs. statistical or actuarial prediction. Since that time, numerous articles have shown that, given certain information constraints (data adaptable to computer use and the relative unimportance of rare events), the computer has been favorably compared with the clinician in predicting future behavior and assigning a person to a diagnostic group. Adams (1974) automated the interpretation of neuropsychological test data. Spitzer, Endicott, Cohen, and Fleiss (1974) and others have developed programs to given DSM II diagnostic categories. Griest, Klein, and Erdman (1976) used a computer that queries the clinician to produce diagnoses according to research diagnostic criterion. Lefkowitz (1973) used multivariate procedures to predict marriage adjustment and did as well as a clinician. While Duckworth and Kedward (1978) used standardized interview techniques to give reliable symptom ratings and precise diagnosis. One could go on, but the message is clear: Given the same information as a clinician, a computer is extremely reliable and most often does as well as or better than the clinician in diagnostic classification. At this point, some ask, "So what?" Diagnostic categories may not be that useful anyway. Levels of functioning (or some other approach to description) may be more useful. Computers can play a role in facing such questions.

\section{THE COMPUTER AS INTERVIEWER}

Within psychiatry, computers have been used to interview patients, but they are more commonly used to process and handle previously collected information. There are several large-scale computerized psychiatric record systems in existence. Greenes, Pappalardo, Marble, and Barnett (1969) describe the MUMPS system in operation at Massachusetts General Hospital. At the Institute of Living in Hartford, Connecticut, the emphasis has been on the use of daily behavioral checklists to monitor patient behavior regularly (Glueck \& Stroebel, 1969; Rosenberg \& Glueck, 1967; Stroebel \& Glueck, 1970). At Rockland State Hospital, a multistate system encompassing 120,000 hospital beds has been developed to include automated versions of nursing notes, personality inventories, drug control forms, mental status examinations, developmental histories, progress notes, and patient movement reports (Cancro, 1970). Sletten, Ernhart, and Ulett (1970), Sletten, Schuff, Altman and Ulett (1972), and Sletten, Ulett, Altman, and Sundland (1970) describe a system that has been in operation in Missouri since 1966, which uses a checklist mental status exam plus several structured person-administered interviews to provide demographic, diagnostic, and prognostic statements about patients. These recordkeeping systems are expensive, are highly complex, require a large supporting staff, and require extensive effort to put into operation.

Others have used a computer to interview psychiatric patients directly. Maultsby and Slack (1971) used a LINC computer and a cathode-ray screen with keyboard to elicit general information concerning an individual's personal, family, social, educational, marital, and financial situation. Responses of special interest are followed by more detailed questioning. The information collected is organized and printed out as a computerized report that is made available to psychotherapists who are either evaluating or working with the patient. Mayne, Weksel, and Sholtz (1968) have developed a system using a cathode-ray screen and a $16-\mathrm{mm}$ film frame presentation. Greist, Gustafson, Strauss, Rowse, Langren, and Chiles (1973) have a computerized interview to collect information to be analyzed in order to predict the potential for suicide. Patients are interviewed via a cathode-ray screen typewriter with both multiplechoice and open-ended questions. In a study comparing computer and clinician prediction of suicide attempts for 22 patients who had expressed suicidal ideas and 43 nonsuicidal psychiatric patients, the computer was $70 \%$ accurate in predicting attempts, whereas the clinicians' hit rate was $40 \%$. In predicting nonattempts, the clinicians did slightly better than the computer, with $94 \%$ vs. $90 \%$.

Slack and Slack (1977) compared structured interviews performed by a computer with those performed by a physician and found that the content of what the physician was told was affected by the time of day and by the interviewing sequences. This was not true of the computer. Angle, Hay, Hay, and Ellinwood (1977) have computerized a comprehensive behavioral assessment that takes between 4 and $10 \mathrm{~h}$, and yet they report that clients, in most instances, prefer the computer to human interviewers. Blankenship (1976) computerized the Schedule of Recent Life Experience, and although it was not particularly liked by the person interviewed, the computer acquired information that was accurate. Lucas, Mullin, Luna, and McInroy (1977) and Reich, Robins, Woodruff, Taibleson, Rich, and Cunningham (1975) used a computer to screen for alcohol-related problems. Lucas et al. found that people told a computer that they consumed $30 \%$ more alcohol than they told a human interviewer.

\section{COMPUTER AS TESTER}

Much of the early work of automating the administration of psychological tests was done by noncomputer means. Elwood (1960) has spent several years automating the Wechsler Adult Intelligence Scale (WAIS). His system is a paper-tape-controlled solonoid-operated console with speaker, rear-projection screen, microphone, 
pushbutton response panel, tape recorder, and teletypewriter. Elwood and Griffin (1972) report the results of studies comparing the automated version of the WAIS with the traditional face-to-face administration. Using a test-retest paradigm, they found that the automated version was as reliable as the traditional WAIS. In comparing the automated version with the standard face-to-face administration, they report correlations for the verbal IQ of .92 and .95 , for performance IQ, .93 and .88, and for full-scale IQ, .95 and .96 . These results suggest the automated version compares quite favorably with the traditional administration. Elwood and Griffin did find that the automated performance IQ tended to be lower than face-to-face administration. The difference seemed to be attributable to their automated version of the digit symbol subtest.

Overton and Scott (1972) have automated the Peabody Picture Vocabulary Test, using a projectorrecorder to provide simultaneous audio and visual stimuli. In order to respond, the subject presses the panel that contains the appropriate picture. Overton and Scott used various combination of Forms A and B with 240 retarded individuals in order to compare the automated and hand-administered versions. They report correlations in the range of .91 to .94 . The automated version resulted in a higher rate of initial failures to reach basal performance. Overton and Scott suggest that careful preinstruction and training would probably overcome the higher failure rate.

In another attempt at a noncomputerized automation of psychological tests, Brinton and Rouleau (1969) used an automatic slide projector to present the Hidden Figures Test. Each line was encoded to enable a photocell to detect a correct answer. A subject made choices by throwing a toggle switch, and an electromechanical printer recorded the response time.

More recently, efforts have been made toward computerized administration of psychological tests. Using college students as subjects, Hedl, O'Neil, and Hansen (1973) compared computer and hand-administered Slosson Intelligence Tests (SITs) with the results of the WAIS. Using 1 week between testings, they found a correlation of .75 between the computer and handadministered SITs. The computer-administered SIT correlated with the WAIS at .54. The hand-administered SIT correlated .52 with the WAIS. Hedl et al. also reported that the computerized version led to higher levels of state anxiety, which they attributed to a complex interaction between the nature of the test and the quality of the computer programming. Hansen and O'Neil (1970) and Lushene, O'Neil, and Dunn (1972) report contrary findings regarding state anxiety.

Elithorn and Telford (1969) used a PDP.8 with an oscilloscope and teletypewriter to measure intelligence using a multiple-choice nonverbal route-finding maze task. Unlike other intelligence test developers, who lock at a number of items passed or failed. Elithorn and Telford's interests were in examining the process by which individuals solve the maze task. Gedye and Miller (1969) used an automated system called the ts 512 , which utilizes a $35-\mathrm{mm}$ film strip with a rearprojection screen and two response buttons. Teletypewriter, paper tape, and magnetic tape are used to control the process and record the information. Gedye and Miller used a pictorial paired associate learning test that presents a series of graded lessons. Although the system was designed for testing geriatric patients, Gedye and Miller report that subjects of all ages responded well to the automated testing. Some geriatric patients who refused face-to-face testing accepted a computerized presentation.

Dunn, Lushene, and O'Neil (1972) tested 77 undergraduate college students, using an automated administration and scoring of the MMPI. They recorded the response latencies for the items and used a stepwise regression analysis to discover that item length accounted for $48 \%-58 \%$ of the variance, whereas item ambiguity, social desirability, and dispersion accounted for only 3\%-8\%. For the MMPI critical items, the deviant response latencies were longer than nondeviant response latencies. In general, these findings suggest that latency may not always have the psychological significance of ten attributed to it.

Space (1975) describes a console for the computer administration of the PPVT (later described in Klinge \& Rodziewicz, 1976), and the Kelly Role Construct Repertory Test. A microcomputer-administered version using a CRT and random-access audio generation is described in Space and Huntzinger (1979). Gilberstadt, Lushene, and Buegel (1976) have automated the Raven Matrices and the digit symbol and digit span subtests of the WAIS. Scissons (1976) computerized the California Psychological Inventory, and Karson and O'Dell (1975) computerized the $16 \mathrm{PF}$ test. As these efforts indicate, a number of different psychological tests have been computerized and the results appear promising.

\section{THE COMPUTER AS REPORT WRITER}

The most commonly used computer-generated report uses information from the MMPI. Several versions exist (Finney, 1966; Fowler, 1980; Lachar, 1974; Swenson, Rome, Pearson, \& Brannick, 1965), and available evidence suggests the reports are useful in clinical settings and have been well received by mental health professionals. For example, Bringmann, Balance, and Giesbrecht (1972) compared computer-generated and graduate student-written reports and found no significant differences in content or style. Fowler and Miller (1969) offered the automated MMPI report to 352 psychiatrists and 54 psychologists and found favorable responses. Webb (1970) and Webb, Miller, and Fowler (1970) used clinicians to evaluate the MMPI reports and found the reports to have substantial validity, clarity, and utility. Kleinmuntz (1967) used five MMPI profiles analyzed both by computer and by clinicians. He found 
that the computer surpassed the average clinician and did as well as the best of the eight clinician test interpreters.

In the case of the MMPI, the reports have taken information from a single psychological test and yet have been judged clinically useful. The results from a series of psychological tests integrated into a report should be of even greater usefulness. Paitich (1973) has attempted to integrate the results of a battery of psychological tests. The Raven Matrices, the MMPI, the 16 PF Form C, the Clarke-WAIS Vocabulary Test, the Clarke Parent Child Relations Questionnaire, and a sexual history questionnaire were administered by a psychometrician, and the data were transmitted to a computer via punch cards. A report was written that encompassed a score/percentile profile along with several sentences briefly describing the results of each test. In instances in which the output from individual tests are contradictory, the descriptions are eliminated. Although this system is still in its developmental stages, Paitich reports that after 1 year (in 1973) of existence, it seemed to have been well accepted as the only psychological assessment for the bulk of inpatients and outpatients.

Gilberstadt et al. (1976) have an automated report using the Raven Matrices and the digit span and digit symbol subtests, as mentioned earlier. In addition to smaller scale reports, systems exist that attempt to put together information from numerous scales (Greist \& Klein, 1980; Johnson \& Williams, 1980).

\section{REASONS FOR THE COMPUTER AS PSYCHOMETRICIAN}

From the foregoing, it is evident that computers have a useful role in the delivery of psychological services. The following are reasons why.

(1) There appears to be an ever-increasing demand for psychological services, and a common complaint is the extended times between referral, testing, preparation, typing, and return of the report. A computerized battery of psychological tests, coupled with automated scoring, interpretation, and report writing, can literally reduce the "turn-around" time between completion of testing and return of the report from a typical time of 14 days to within $30 \mathrm{~min}$ or less. With the use of additional terminals in a networking mode, the time between referral and testing can be made as short as is econom. ically feasible.

(2) Computerized administration of psychological tests uses a trained clerk rather than a psychometrician or psychologist. This has two immediate advantages. First, it frees the psychologist from routine and repetitious testing to devote additional time to more complex considerations, such as psychodiagnosis beyond standard computer-retrieved information, psychotherapy, community preventive work, and research. Psychological tests have often been criticized as needing additional validity information. Free time could be used for improving the quality of psychological tests. Second, it is surely more economical in personnel cost to use a computer-clerk combination rather than a psychologist or psychometrician. Elwood and Griffin (1972) did a cost analysis on the automated WAIS and found that the relative cost ratio of a clerk/typist team doing a hand administration to the automated version was $.52 / .42$. Johnson and Williams (1980), in examining the cost of traditional evaluations compared with those by a computerized system, found the computer evaluations to cost about half as much (equipment costs excluded).

(3) The computerization of psychological tests provides the opportunity for research that was heretofore extremely difficult or impossible. For example, Dunn et al. (1972) were able to study MMPI latencies through computerization. Also, the data collected by computerized administration can be stored in a form that is immediately available for concurrent or future research. This direct storage of data should reduce the probability of errors by eliminating the human handling of data.

(4) Although further research is required, computerized administration of psychological tests can potentially increase the reliability of the tests by reducing the variability that enters into the testee/tester encounter. A classic weakness of the human examiner is to "give the benefit of the doubt" to a testee in such a generous way that violence is done to the normative interpretation. The effects of response bias on test results have been documented by Cronbach (1964), Edwards (1957), and Rosenthal (1968). They point to such factors as responding to confirm the experimenter's hypothesis, when in doubt agree, and to protect yourself, provide a socially desirable answer. There is some preliminary evidence that suggests that such biases are reduced through computerized administration. Evan and Miller (1969) found that individuals answering questions to a teletypewriter gave more "honest and candid" answers to the machine than they did to a human interviewer. In contrast to this thought, Koson, Kitchen, Kochen, and Stodolosky (1970) found no difference in response biases in individuals questioned by an experimenter vs. a computer.

(5) In addition to automated psychological testing, there also appear to be several advantages in using computerized reports in clinical practice. A computerized report is absolutely reliable in the sense that entering the same data into the computer always results in the same report. Computers do not get involved in family disagreements prior to coming to work. In addition to being more reliable, the computer also has the capacity for being more consistent in the amount and type of information included in a report. The base of interpretation rules can be updated easily as new research is done, and it can reflect local norms, as well.

(6) The use of computers to administer and score psychological tests provides the opportunity to use tests that are considered clinically useful, such as the Kelly 
Role Construct Repertory Test, but have not been widely available because they are very difficult to administer or score manually.

(7) Although it may be economically infeasible to program for the "rare" event, computerized reports do provide an impetus for using the best clinical decision making rules available in the profession. That is, the knowledge of the best clinicians becomes more widely available. This has two advantages. One, it encourages mental health professionals to be clearer in the articulation of their decision making rules. Second, if the rules were to come from the "best" clinicians, the hit rate should be maximized and, therefore, be well above that of the average clinician. A number of studies suggest that this is not an unreasonable expectation (e.g., Goldberg, 1970; Kleinmuntz, 1967).

(8) The use of automated psychometric services may increase the range of knowledge available at any given clinical setting. For example, mental health professionals often encounter individuals with rarely seen characteristics with which they have not had the opportunity to build a base of clinical experience. Thus, they lack information and experience in dealing with this type of person. Computer storage of norms would provide immediate access to such "experience."

(9) Unstructured interviewing has long been considered to be of low reliability. Different interviewers cover different information. Differing interviewer styles elicit different content. For example, an aggressive interviewer who challenges a patient is more likely to elicit data suggesting patient hostility. Endicott and Spitzer (1972) report that interrater agreement for a structured interview is "highly reliable," with coefficients generally higher than those of unstructured interviewers. Sletten et al. (1970) examined the reliability of a checklist mental status form and found both item and scale reliabilities to be in the $.80 \mathrm{~s}$ and $.90 \mathrm{~s}$. Coddington and King (1972) readministered an automated history to five mothers 1-4 months after the initial administration and found the history scores to be almost identical.

(10) The interview material that makes its way into medical records is often illegible, frequently has missing information, is difficult to extract from, often has no standard organization, and may have contradictions both within the history and from history to history. Grossman, Barnett, McGuire, and Swedlow (1971) had two physicians evaluate medical records and found the above shortcomings but discovered a high degree of agreement between an automated medical history and the physician's records. Computer-written reports would eliminate the above difficulties because they would be legible and would contain standardized material in a standard format. Inconsistencies would arise only in patient answers, which initially would be useful clinical information. Furthermore, Grossman et al. (1971), Slack, Hicks, Reed, and VanCura (1966), and Stead, Heyman, Thompson, and Hammond (1972) found that automated procedures collect more information than the physicians themselves do. In a highly mobile population, the computerized interview and report can provide reproducible and transmittable formats to follow individuals who seek treatment at other facilities.

(11) History taking is generally time-consuming, and it is not uncommon for physicians to use secretaries and receptionists to collect a history. Self-administered questionnaires would help, but these often contain numerous questions that need not be answered by all individuals. In addition, it is not efficient or pleasant to thumb through many pages of answered questions. An automated interview is able to branch to relevant questions and organize the material into a readable format with significant data highlighted.

(12) An automated interview allows a patient to proceed at his own pace. Research with schizophrenics by Steffy (Note 1) suggests that process schizophrenics maximize their communication in an interview when the interviewer sets a pace of information flow as slow as the subject.

(13) The storage of standardized interview data allows for an analysis of clinical profiles to assess the demographic, historical, and clinical variables and to make them useful for predictions of such things as treatment, use of drugs, suicide, homicide, and so on. With the continual collection of data, local norms can be continually refined with each new patient.

\section{ARGUMENTS AGAINST THE CONCEPT OF COMPUTERIZED ASSESSMENT}

The use of computer-aided psychological testing and interviewing is not without criticism. The following is a review of such criticisms and comments with respect to them.

(1) A computer-administered psychological evaluation or interview is depersonalizing to the patient subject. He is left feeling he is an object of mechanical and electronic manipulations, which interferes with the establishment of patient-physician rapport and increases the patient's isolation in an increasingly mechanistic world. (2) Computerized approaches describe an individual as a point on a continuum in comparison with the rest of the population, but they are not geared to regularities and patterns unique to that single individual. Thus, the clinically more important idiographic information is lost in favor of nomothetic information. (3) Computerized approaches do not allow complex inferences about the psychodynamics or motivating structure underlying an individual's behavior. Only the behavior is tapped, and the richness and complexity of it is lost. (4) A computerized test or interview is an "externally run" event that does not allow either subject or clinician the feeling of effective control in the situation. (5) Psychological tests are generally not valid to begin with. (6) Computerized approaches are static in form. They neither adapt to the patient's style of responding nor permit spontaneous changes in focus that lead to rich 
sources of diagnostic information. (7) Computerized approaches are not efficient or economical to use with the highly difficult subject. Thus, the hyperkinetic destructive child, the delinquent, the uncooperative malingerer, and the severe psychotic unable to cooperate are all poor candidates for computer-controlled testing and interviewing. (8) A clinician is necessary to stimulate, inhibit, and vary the flow of diagnostic information. The computer cannot detect when the subject is in trouble expressing what he wants to say or when he is unloading so much emotional material at one time that the session is not in his best interest. (9) The problems of invasion of privacy, the culturally unfair interpretation of the test results, and the confidentiality of testing, inherent in all psychological testing, are magnified when testing is conducted by a machine. (10) The computer cannot discriminate between normal error and pathological response. (11) One of the great values of psychological testing is not the standardized procedures and quantified test scores, but the behavioral observations that give rise to clinical inferences. The computer-controlled devices cannot be geared to sense all of these. (12) Automated procedures that involve statistical or cookbook procedures tend to result in trivial decisions, such as placing an individual into a diagnostic category to which he is already known to belong. Prediction of behavior, treatment choice, and other events of greater interest are not undertaken. (13) Automated procedures introduce bias into the interview and/or testing situation.

Criticisms of psychological assessment are, as a group, not without merit. They demand attention, analysis, and response. However, in general, I would argue that the sound advantages of computer-assisted assessment outweigh the sound criticisms.

First, it must be remembered that the computerassisted psychological assessment procedure, like any other computerized procedure, is not devoid of human interaction. Evidence quoted elsewhere in this paper indicates that when the computerized procedure is thorough and the patient feels the service being given him is comprehensive, he may feel more, not less, favorably inclined to the computerized approach and to his psychotherapist. With regard to patients in psychotherapy, it is well-known that psychological testing, physical examination, or standard mental status interview by the therapist detracts from the therapeutic situation, in which a large measure of responsibility is placed upon the patient to initiate the exploration of problems. For this reason, such procedures are of ten referred to someone else, in order that they not interfere with the ongoing therapy. To do so, however, can run the risk of conflicts in rapport and transference if another professional person conducts these diagnostic chores in a quasitherapeutic manner. Thus, computercontrolled psychological testing can alleviate this risk and yet produce the needed diagnostic information for the psychotherapist. Computerized psychological testing and interviewing as a screening device covering routine historical and testing information can enhance clinical decisions. The interview data, for example, can be made available to the clinician prior to his initial contact, thus enabling him to focus on issues of most relevance to the patient and himself. This eliminates the need for many questions and answers and frees the clinician to establish rapport and use his clinical acumen in the most efficient way. Although further research is required, the studies previously reviewed indicate no difference in rapport when using an automated medical history.

As far as behavioral observations are concerned, computerization would not ignore this important element of psychological testing. Gedye and Miller (1969), in describing their automated procedures, have noted that the testing situation is "a very rich source of behavioral data." Klinge and Rodziewicz (1976) state that they have found it useful to observe testee behavior during computerized testing. The computerized procedures would be assisted by a trained clerk, who would make such behavioral observations and also be available when the computer and/or subject indicated that help was needed. The behavior observations could be typed into the computer by the clerk. Not only free narrative behavioral description could be integrated into a report, but also certain coded dimensions of behavior could be brought to bear on the validity and the interpretation of the test results. This procedure shows the promise of having greater economy and greater coverage than the use of a clinician alone. Meanwhile, the clinician is free to attend to more complex and subtle issues in behavior observations, diagnosis, and therapy.

The advantages of trained nonprofessionals for behavioral observations and ratings are well established. Studies of reliability (Cromwell, Note 2) have indicated that ward attendants do better than psychotherapists in making behavioral ratings, as viewed separately from the interpretation of such ratings.

For ongoing research and development, it is important that the investigators be in close contact with the thought and action of clinicians after providing them with computerized reports. In this way, procedures may be designed to sense and eliminate certain problems and conditions in automated assessment, to extend coverage of relevant data, and to articulate further the clinical decision making based on these data. No matter how many advances are made in sophisticated computer assessment, it is assumed that the clinician will always represent a frontier in providing information and decision making before it has been translated into universal application by computer techniques.

Since computer assessment, at least as it is conceptualized in this era of development, is a failry structured information-getting exercise, there is no danger, as in the open-ended interview, that the patient will "unload" more information than is advisable for this emotional state. It is obvious that there is no way this additional 
information would be recorded. Lieberman, Yalom, and Miles (1973) find encounter groups led by tape-recorded instructions are remarkably free from psychiatric casualties because of the limited opportunity for such unloading. On the other hand, the computerized assessment procedure will indeed have procedures by which to encourage or correct the subject in order to elicit the necessary information.

Some criticisms are made simply because people have not envisioned the flexibilities and capabilities that computer-assisted psychological assessment and interviewing can and do have. For example, the valuable idiographic data, reflected by regularities in clinically significant behavior unique to a given subject, may be more accurately identified or keenly sensed by computer techniques than by traditional clinical observations if programming is adequate. The Kelly Role Construct Repertory Test, which identifies the recurrent trends in the way subjects tend to conceptualize other people and events, is an example of this. By definition, these recurrent practices of adaptive or maladaptive conceptualizing of given people or events may be referred to as conceptual structure. With this technique, stable conceptual patterns almost invariably are identified that neither the subject himself nor the clinician was aware of before the testing.

The same facility of computer-assisted test analysis that allows the treatment of normative data also allows the discrimination between sporadic normal error and pathological response. Pathological responses typically fall into a known normative pattern, and sporadic error or malingering can be separated out. The "lie score" and "validity score" of the MMPI are illustrations of this technique. In any case, such errors and pathological indicators can be reported to the clinicians who use the test results so that they can exercise further evaluation of this validity. In some cases, the computer is programmed to sense the familiar errors in test response immediately, so that auditory and visual corrective instruction can be given. Pacing can be subject-controlled during computerized assessment as easily as or more easily than with tests administered by a psychometrician or clinician. In that sense, the subject need not have the feeling that the automated procedure is an externally run event.

Insofar as criticisms of psychological testing in general are concerned, independently of computer-assisted procedures, some remarks are appropriate regarding validity, invasion of privacy, and confidentiality. No psychological test has perfect reliability or perfect validity. Many have demonstrable validity only in large-sample validity studies but have limited significance on an individual clinical level. Studies will continue to identify and account for the sources of variance that have seemed to limit the predictability of a given test at a given time. As long as an identifiable degree of validity exists, the crucial question remains, "What can be substituted that could be better?" In the diagnosis-treatment chain of events, one suggestion has been to do no testing at all and, therefore, to offer no prejudgments as labels. This viewpoint would ignore the premise that information is a useful prerequisite to decision making in psychiatric treatment. If one concedes that information is important but can be gathered merely in the process of psychotherapy, then it becomes hard to reject the idea that this information should not be recorded and its diagnostic utility examined. If so, of course, narrative data would usually prove inferior in coverage, reliability, and validity to psychological testing. When tests are used in screening for a given treatment, vocation, or training program, the argument is often made to give everybody a chance. Indeed, if the possibility is such that everyone could have a chance, there would be no point in screening. Testing would serve only to explain the relevant factors so that everyone could have an improved chance at eliminating all possible negative factors. A number of real-life situations exist in which only a limited number of people get a particular opportunity (e.g., for hemodialysis or other rare treatment programs, for colleges, for specialized training programs, etc.). When such is the case, the individuals responsible for the decision of who is "picked" usually want to know who will have the best chance of profiting. To reject psychological testing in favor of interview or some other method to gain this information becomes disastrous as far as the validity of selection is concerned.

A valid criticism of psychological testing has concerned the interpretation of tests based upon culturally unfair norms. When a majority group member on whose group the norms are based takes a test, a valid prediction of his outcome can likely be made. When a minority group member gives the same response, an invalid prediction about him may arise because his response is not mediated via the same cultural experiences through which the original valid prediction was made. To resort to open-ended interviews in such cases would be to shift from one invalid and biased procedure to another. Computerization becomes advantageous in such cases, because more complex and subcategorized norms can be generated from community and national data. This would allow a given response to receive different interpretations depending on what was appropriate for the individual.

Regarding confidentiality, the problems are important and present, independently of whether computer procedures are used. Individuals can misuse confidential information whether it is in conventional record form or stored by computer. Thus, the only answer to this criticism is that strong ethical controls must always be exerted to protect the rights of an individual at times, first, when he is divulging information in the interest of getting the best service possible and, second, when he needs to appeal when an incorrect datum or decision regarding him has actually been recorded. There are also methods of limiting access to computerized infor- 
mation (Ford, 1976) that reduce the chances of misuse.

The problems of computerized testing of the uncooperative, difficult, confused, or disturbed subject lie on the same continuum with the problems of conventional testing of such subjects. Such subjects under some circumstances do not yield valid test results. The likelihood that this would be greater with computer-assisted procedures is not entirely clear. The more expensive equipment in the computerized testing situations would probably lead to greater caution. Otherwise, the major factor of cooperation depends upon the clerk in charge of testing. The personal approach of this person is relatively independent of whether he or she is using tools that include computer-assisted procedures.

\section{BUT WILL THEY USE IT? PATIENT RESPONSE TO COMPUTERIZED INTERVIEWING}

Several systems for computer collection of medical and psychiatric information have been described. A computerized interview may be efficiently organized with respect to its ability to branch to appropriate questions and to store and present information in a meaningful way. Yet, it may be of minimal usefulness if individuals either refuse to interact with the computer or are highly resistant to providing information. Thus, it is important to examine patient acceptance of this procedure. To date, most (an exception noted earlier) of the questionnaire surveys involving medical and/or psychiatric interviewing report patient acceptance to be highly favorable. Haessler (1969) used an automated medical history with 200 patients and reports $66 \%$ had no preference with respect to machine or physician, $29 \%$ preferred the machine, $10 \%$ preferred the physician, and $5 \%$ preferred the nurse. Of those patients, $79.5 \%$ reported the procedures interesting, and $2 \%$ of the suicidal patients interviewed preferred the terminal. Mayne et al. (1968) report that of 159 patients, only 3 refused to be interviewed. The response to the interview was overwhelmingly favorable. Slack et al. (1966) indicate that 18 patients preferred the machine, 12 preferred the physician, and 20 had no opinion. None actually disliked the computer. Grossman et al. (1971) report that $91 \%$ were seldom bored and that most felt that the questioning was relevant. They state, though, that preference for the computer vs. the physician was mixed. Coddington and King (1972) relate that $67 \%$ of the mothers interviewed felt they were able to be as frank with the computer as they were with the physician. Fifteen percent felt they could be more frank; $50 \%$ found interaction with the computer easier and $37.5 \%$ found it harder. Stead et al. (1972) report that 49 of 50 patients interviewed for headache difficulties found the procedure interesting and enjoyable. Maultsby and Slack (1971) report that $90 \%$ of the patients found the procedure not difficult, but enjoyable and interesting. Fifty percent preferred the machine, and $30 \%$ preferred the physician.

Klingler, Johnson, and Williams (1976) found that
$68 \%$ of the patients liked being tested on a computer and $91 \%$ said they were as truthful $(45 \%)$ or more truthful $(46 \%)$. In summary, although further studies of psychiatric interviewing are needed, the data to date suggest that patient acceptance has been generally favorable. It does not appear to be an obstacle in the use of computers for psychiatric interviewing.

\section{ACCEPTABILITY TO PROFESSIONALS}

In evaluating the utility of a computerized system, each link must be examined separately for strengths and weaknesses. Thus, although the computer may be efficient and the patient acceptance favorable, if professionals do not accept the system or find it helpful, computerized interview is of questionable value. The acceptability by professionals reported in the literature tends to be anecdotal and not backed up by statistical information. Both Laska, Simpson, and Bank (1969) and Mayne et al. (1968) report that psychiatrists find computer printouts of mental status exams and psychiatric histories useful and time-saving. Grossman et al. (1971) reported that physicians saw no differences in rapport or efficiency when using the automated mental medical history. The physicians were not as favorable as the patients in their acceptance of it. Grossman et al. suggest that this may be due to the fact that physicians ask questions to confirm hypotheses or develop management and disposition plans. Maultsby and Slack (1971), however, found more positive results when investigating the use of an automated history with psychotherapists both before and after interviewing a patient. In $70 \%$ of the cases in which psychotherapists used the report prior to seeing the patient, the report was considered helpful. Thirty-nine percent said it saved them time, but $27 \%$ indicated it took more time. For those psychotherapists who read the report after the interview, $45 \%$ labeled the procedure helpful.

Glueck, Bullotta, and Ericson (1980) discuss the automated nursing note that has been in use for 12 years at the Institute of Living. They report mixed reviews among staff, many of whom, after the first 3 years of use, saw it as not being clinically useful. Johnson, Williams, Giannetti, Klingler, and Giannetti (1977) disucss the problems they have had with staff acceptance at the Salt Lake City, Utah, VA Hospital.

It is clear that professional acceptance of computerized mental health care is the weakest link in the chain of elements discussed so far. Acceptance has been variable and there may be ways of overcoming some of the problems. Klonoff and Clark (1975) report that staff attitudes toward computers were favorable for those attending a 2.5-day course on computer systems. Johnson et al. (1977) suggest making a report that evolves around the problems of patients, not around the tests administered. Too many data are overwhelming, and repetition of format becomes boring. Johnson et al. (1978) state that there is a need for staff to understand 
the rationale behind a computerized system. Education and considerable preparation are important for change.

Gradually, introducing the use of computerized assessments may help reduce problems, particularly if staff can see the introduction of computers as enhancing their work rather than taking over for them. As Baer, Johnson, and Merrow (1977) indicate, it is uncertainty that limits the use of new technologies.

\section{CURRENT TESTS VS. NEW TESTS}

Now that we have stated why it appears computerized psychological testing is a viable approach, what kinds of tests should be computerized? Like a human tester, the computer has a set of demand characteristics and is not necessarily neutral in the testing situation. For example, Scissons (1976), in comparing a computerized California Psychological Inventory with a paper-andpencil version found more items not answered via computer administration. As noted, this may have resulted from the constant reminder that one of the choices was to omit the question. Biskin and Kolatkin (1977) found differences between the computer and regular administration of the MMPI on the "cannot say" scale, as well as minor differences on the paranoia scale. Although the evidence suggests comparable results between hand- and computer-administered tests, design of test administration may affect the outcome. One approach is to adapt current tests for computers, such as Costar's (1975) multiple-choice version of WAIS vocabulary.

Computerizing commonly used psychological tests has certain advantages if available norms still apply. Professional familiarity is also an advantage. However, to use the computer effectively, tests designed especially for it will add depth to any test battery. The computerized MMPI does not use the computer's capabilities and may not be a cost-effective approach. It would tie up a terminal for approximately $1.5-2 \mathrm{~h}$ answering sequential true-false questions, when an optical scanning of penciled answers could do as well.

The use of simple branching techniques to select the most relevant interview questions or psychological tests is a step toward using the capability of the computer. Johnson, Giannetti, and Williams (1979) have used response contingent questions in their Psychological Systems Questionnaire. For example, they have eliminated irrelevant questions, such as those pertaining to marriage when the testee has never been married. Others have suggested using mathematical or algorithmic methods to improve the efficiency of branching decisions. Warner, Rutherford, and Hautchens (1972) have developed a Bayesian approach that calls for a recalculation of the probabilities each time a question is asked. Glaser and Collen (1972) have proposed an algorithm to choose interview questions in such a way as to reduce uncertainty maximally. They have applied this to the diagnosis of diabetes. Another approach could be called a dictionary approach. Narrative responses could initiate a dictionary search to identify key words, pairs, and so on, that would serve as indicators for the next question(s). Unfortunately, the algorithmic and Bayesian approaches require previously collected norms from which a priori probabilities are to be calculated. Of course, the capability of the computer to collect local norms is one of its strengths.

As problem areas are identified, either through recording initial problem statements or eliciting problem areas in testing, the computer could use branching techniques to select the most relevant tests. Over time, tests can be added or deleted as use dictates. Another method for reducing testing time would be the stradaptive strategies of Weiss (Note 3), used by Sapinkops (1978) with the California Psychological Inventory. Sapinkops found it took $67 \%$ fewer items. It did encounter some reliability problems in trait estimates, but he felt the approach merits further investigation.

Certain tests that have considerable clinical utility but are difficult to use in paper-and-pencil versions, such as the Kelly Role Construct Repertory Test, become very easy to use when computerized (Space \& Huntzinger, 1979).

Finally, the computer can be utilized to collect physiological data or information that appears to be promising in diagnosing certain disorders. Cromwell (Note 2) has argued that conventional diagnostic systems have failed and new approaches, such as using span of apprehension and reaction time crossover, are likely to be more helpful than current approaches are.

\section{WHAT KIND OF COMPUTER?}

Denner (1977) has argued that many psychological tests can be automated without computers. To be sure, this is possible, but one loses many of the advantages outlined earlier in this paper.

One approach to automating psychological services is to use a large computer with timeshared terminals. If the computer is present and connect charges are minimal (which is not always the case), this can be an inexpensive way to go. However, as DeWitt and Weiss (1976) point out, response times can be burdensome, with $15.20 \mathrm{sec}$ usual and $40-45 \mathrm{sec}$ not unusual. This would considerably lengthen testing and preclude accurate latency and similar measurements.

Minicomputers offer a second solution, and one that would certainly work. Minicomputers, although less expensive than large main frames, are still expensive to use in a stand-alone application such as psychological testing. If a minicomputer were to be used in a timesharing application, response times would be likely to be considerably faster than those reported by DeWitt and Weiss (1976). When simultaneous time-critical measurements (e.g., physiological) are not needed, the response 
times may be quite satisfactory, for a limited number of terminals. A disadvantage is that minicomputer manufacturers usually develop their own software and one may be restricted as to choice. The software is often expensive, as well.

The wave of the future appears to be a series of small stand-alone microcomputers as part of a network, such as Xerox's proposed Ethemet. A stand-alone microcomputer with $64 \mathrm{~K}$ bytes of memory, floppy disk, CRT screen, and operating system costs less than a terminal did a few years ago. In a network, programs could be down-loaded from a larger disk system and data collected could be stored on resident minifloppies for later transmission to a report-writing program. Add a way of generating audio responses to assist in error correction during test administration, as well as to aid the visually impaired or nonreader, and one will have a very sophisticated "psychometrician." Over the long haul, this is likely to prove very cost-effective.

\section{IN CONCLUSION}

This paper has examined the application of computers to the services traditionally provided by a psychometrician. The declining costs of powerful computer systems, the increasing costs for provision of psychological services, and the many advantages of using computers in mental health services are likely to lead to an ever-increasing use of computers in the delivery of these services. The computer cannot replace the psychologist or psychometrician, but it can provide a number of services, including information gathering via interview, psychological testing (including the collection of physiological/reaction time-type variables), interpretation of psychological tests, and the integration of various sources of data into a comprehensive report. This report could then be utilized to provide more effective mental health services. A computer could also be used for limited educative-therapeutic treatment. The application of computers is as creative as the people behind them. Although not a god to be worshipped, the computer can be a very useful extension of the mind.

\section{REFERENCE NOTES}

1. Steffy, R. A. Personal communication, September 1, 1979.

2. Cromwell, R. L. Project on classification of emotionally disturbed children. Paper presented at Southeastern Society for Multivariate Experimental Psychology, Atlanta, Georgia, April 1972.

3. Weiss, D. J. Strategies of adaptive ability measurement (Research Report 74-5). Minneapolis: University of Minnesota, Psychometric Methods Program, 1974.

\section{REFERENCES}

ADAm8, K. M. Automated clinical interpretation of the neuropsychological battery: An ability based approach. Unpublished doctoral dissertation, Wayne State University, 1974.
Altman, N., Brown, M., \& Sletten, I. W. "And silently steal away." A study of elopers. Diseases of the Nervous System, 1972, 33, 52-58.

Angle, H. V., Hay, L. R., Hay, W. M., \& Ellinwood, E. H. Computer-aided interviewing in comprehensive Behavioral assessment. Behavior Therapy, 1977, 8, 747-754.

Baer, W. S., Johnson, L. L., \& Merrow, E. W. Governmentsponsored demonstrations of new technologies. Science, 1977, $196,950-957$.

Benson, H. The relaxation response. New York: Morrow, 1975.

Biskin, B. H., \& Kolatkin, R. L. Effects of computerized administration on scores on the Minnesota Multiphasic Personality Inventory. Applied Psychological Measurement, $1977,1,543-549$.

Blankenship, L. L. Computer-conducted assessment of lifechange psychological stress. Unpublished doctoral dissertation, University of Illinois at Urbana-Champaign, 1976.

Bringmann, W. G., Balance, W. D., \& Giegbrecht, C. A. The computer versus technologist: Comparison of psychological reports on normal and elevated MMPI profiles. Psychological Reports, 1972, 31, 211-217.

Brinton, G., \& Rouleav, R. Automating the hidden and embedded figures tests. Perceptual and Motor Skills, 1969, 29, 401-402.

Cancro, R. Electronic data processing in psychiatry. Bulletin of the Menninger Clinic, 1970, 34, 12-22.

Condington, R. D., \& King, T. L. Automated history taking in child psychiatry. American Journal of Psychiatry, 1972, 129, 276-282.

Colby, K. M. Artificial paranoia. New York: Pergamon Press, 1975.

Colby, K. M., WATt, J., \& Gilbent, J. A. A computer method of psychotherapy: Preliminary communication. Journal of Nervous and Mental Disease, 1966, 142, 148-152.

COstaR, E. D. Estimation of intelligence and motivation as a screening procedure for programs on PLATO IV. Unpublished doctoral dissertation, University of Illinois at UrbanaChampaign, 1975.

Cronbach, L. E. Response sets and test validity. Educational and Psychological Measurement, 1964, 6, 475-495.

CuthBert, B. N. Voluntary slowing of heart rate: $A$ comparison of various techniques. Unpublished doctoral dissertation, University of Wisconsin, 1976.

Denner, S. Automated psychological testing: A review. British Journal of Social and Clinical Psychology, 1977, 16, 175-179.

DEWITT, L. J., \& WEIss, D. J. Hardware and software evolution of an adaptive ability measurement system. Behavior Research Methods \& Instrumentation, 1976, 8, 104-107.

Duckworth, G. S., \& KedwaRd, H. D. Man or machine in psychiatric diagnosis. American Journal of Psychiatry, 1978, 135, 64-68.

Dunn, T. G., Lushene, R. E., \& O'Neil, H. F. Complete automation of the MMPI and a study of its response in latencies. Journal of Consulting and Clinical Psychology, 1972, 39, 381-387.

EDwards, A. L. The social desirability variable and personality assessment in research. New York: Dryden, 1957.

Elithorn, A., \& Telford, A. Computer analysis of intellectual skills. International Journal of Man-Machine Studies, 1969, 1, 189-209.

Elwood, D. L. Automation of psychological testing. American Psychologist, 1969, 24, 287-289.

Elwood, D. L., \& Grifrin, R. H. Individual intelligence testing without the examiner: Reliability of an automated method. Journal of Consulting and Clinical Psychology, 1972, 38, 9-14.

Endicotr, J., \& Spitzer, R. L. The value of the standardized interview for the evaluation of psychopathology. Journal of Personality Assessment, 1972, 36, 410-417.

Evan, W. M., \& Miller, J. R. Differential effects on response bias of computer versus conventional administration of a social 
science questionnaire. Behavioral Science, 1969, 14, 216-227.

Finney, J. C. Programmed interpretation of MMPI and CPI. Archives of General Psychiatry, 1966, 15, 75-81.

Fond, W. E. A client-coding system to maintain confidentiality in a computerized data system. Hospital and Community Psychiatry, 1976, 27, 624-625.

Fowler, R. D. The automated MMPI. In J. B. Sidowski, J. H. Johnson, \& T. A. Williams (Eds.), Technology in mental health care delivery systems. Norwood, N.J: Ablex, 1980.

Fowler, R. D., \& Miller, E. Computer interpretation of the MMPI: Its use in clinical practice. Archives of General Psychiatry, 1969, 21, 502-508.

Gedye, J. L., \& Miller, E. The automation of psychological assessment. International Journal of Man-Machine Studies, $1969,1,237-262$.

Gilberstadt, H., Lushene, R., \& Buegel, B. Automated assessment of intelligence: The TAPAC test battery and computerized report writing. Perceptual and Motor Skills, 1976, 43, 627-635.

Glasen, M. A., \& Collen, M. F. Towards automated medical decisions. Computers and Biomedical Research, 1972, 5, 180189.

Glueck, B. C., Bullotta, G. P., \& Ericson, R. P. Automation of behavior assessments: The computer-produced nursing note. In J. B. Sidowski, J. H. Johnson, \& T. A. Williams (Eds.), Technology in mental health care delivery systems. Norwood, N.J: Ablex, 1980.

Glueck, B. C., \& Stroebel, C. F. A computer and clinical decision process: II. American Journal of Psychiatry, 1969, 125, 2-6.

Goldberg, L. R. Man versus model of man: A rationale, plus some evidence for a method of improving on clinical inferences. Psychological Bulletin, 1970, 73, 422-434.

Gorham, D. R., Moseley, E. C., \& Holtzman, W. H. Norms for the computer-scored Holtzman inkblot technique. Perceptual and Motor Skills, 1968, 26, 1279-1305.

Greenes, R. A., Pappalardo, A. H., Marble, C. W., \& Barnetr, G. O. Design and implementation of a clinical data management system. Computers and Biomedical Research. $1969,2,469-485$.

Greist, J. H., Gustafson, D. H., Strauss, F. F., Rowse, G. L., Langren, T. P., \& Chiles, J. A. A computer interview for suicide-risk prediction. American Journal of Psychiatry, $1973,130,1327-1332$.

Greist, J. H., \& KLEIN, M. H. Computer programs for patients, clinicians, and researchers, in psychiatry. In J. B. Sidowski, J. H. Johnson, \& T. A. Williams (Eds.), Technology in mental health care delivery systems. Norwood, N.J: Ablex, 1980.

Greist, J. H., Klein, J. H., \& Emdman, H. P. Routine online psychiatric diagnosis by computer. American Journal of Psychiatry, 1976, 133, 1405-1408.

Grossman, J., Barnett, G. O., McGuire, M. T., \& Swedlow, D. Computer acquired patient histories. Journal of the American Medical Association, 1971, 215, 1286-1291.

HAESSLER, H. A. Recent developments in automating the medical history. Computers and Automation, 1969, 18, 24-27.

Hansen, D. H., \& O'NEIL, H. F. Empirical investigations versus anecdotal observations concerning anxiety and computer assisted instruction. Journal of School Psychology, 1970, 8, 315-316.

Harway, N. I., \& Iker, H. P. Content analysis and psychotherapy. Psychotherapy: Therapy, Research and Practice, 1969, 6, 97-104.

Hedl, J. J., O'Neit, H. F., \& Hansen, D. H. Affective reactions toward computer-based intelligence testing. Journal of Consulting and Clinical Psychology, 1973, 40, 217-222.

Hogan, R. A. Research thoughts toward a computerized therapy. Behavior Therapy, 1971, 2, 107-109.
JENnings, J. A test of the effectiveness of a computer-client interface in a counseling setting. Unpublished doctoral dissertation, University of Mississippi, 1978.

Johnson, J. H., Giannetti, R. A., \& Williams, T. A. Psychological systems questionnaire: An objective personality test designed for on-line computer presentation, scoring, and interpretation. Behavior Research Methods \& Instrumentation, $1979,11,257-260$.

Johnson, J. H., \& Wrlliams, T. A. Using on-line computer technology to improve service response and decision-making effectiveness in a mental health admitting system. In J. B. Sidowski, J. H. Johnson, \& T. A. Williams (Eds.), Technology in mental health care delivery systems. Norwood, N.J: Ablex, 1980.

Johnson, J. H., Williams, T. A., Giannetti, R. A., Klingler, D. E., \& NAKAshima, S. R. Organization preparedness for change: Staff acceptance of an on-line computer-assisted assessment system. Behavior Research Methods \& Instrumentation, 1978, 10, 186-190.

Johnson, J. H., Williams, T. A., KlingleR, D. E., \& Giannetti, R. A. Interventional relevance and retrofit programming: Concepts for the improvement of clinician acceptance of computer-generated assessment reports. Behavior Research Methods \& Instrumentation, 1977, 9, 123-132.

Karson, S., \& O'Dell, J. W. A new automated interpretation system for the 16PF. Journal of Personality Assessment, 1975, 39, 256-260.

KLEINmuntz, B. Sign and seer: Another example. Journal of Abnormal Psychology, 1967, 72, 163-165.

KLINGE, V., \& Rodziewicz, T. Automated and manual intelligence testing of the Peabody Picture Vocabulary Test on a psychiatric adolescent population. International Journal of Man-Machine Studies, 1976, 8, 243-246.

Klingler, D. E., Johnson, J. H., \& Williams, T. A. Strategies in the evolution of an on-line computer-assisted unit for intake assessment of mental health patients. Behavior Research Methods \& Instrumentotion, 1976, 8, 95-100.

KlonofF, H., \& Clark, C. Measuring staff attitudes toward computerization. Hospital and Community Psychiatry, 1975, 26, 823-825.

Koson, D., Kitchen, C., Kochen, M., \& Stodolosky, D. Psychological testing by computer: Effect on response bias. Educational and Psychological Measurement, 1970, 30, 808910.

LACHAR, D. Accuracy and generalizability of an automated MMPI interpretation system. Journal of Consulting and Clinical Psychology, 1974, 42, 267-273.

Lang, P. J. The on-line computer in behavior therapy research. American Psychologist, 1969, 24, 236-239.

LANG, P. J. Behavioral treatment and bio-behavioral assessment: Computer applications. In J. B. Sidowski, J. H. Johnson, \& T. A. Williams (Eds.), Technology in mental health care delivery systems. Norwood, N. J: Ablex, 1980.

Laska, E. M., Siegel, C., \& BAnk, R. Management information systems in mental health. In J. B. Sidowski, J. H. Johnson, \& T. A. Williams (Eds.), Technology in mental health care delivery systems. Norwood, N.J: Ablex, 1980.

Laska, E., Simpson, G. M., \& Bank, R. A computerized mental status. Comprehensive Psychiatry, 1969, 10, 136-146.

LEFKowitz, M. B. Statistical and clinical approaches to the identification of couples at risk in marriage. Unpublished doctoral dissertation, University of Florida, 1973.

Lieberman, M., Yalom, I. E., \& Miles, M. B. Encounter groups: First facts. New York: Basic Books, 1973.

Lucas, R. W., Mullin, P. J., Luna, C. D., \& McInroy, D. C. Psychiatrists and a computer as interrogators of patients with alcohol related illnesses: A comparison. British Journal of Psychiatry, 1977, 131, 160-167. 
Lushene, R. E., O'Nent, H. F., \& Dunn, T. Equivalent validity of a computerized MMPI. CAI Tech. Memo, 1972, 48, 22.

Maultsay, M. O., \& Slack, W. V. A computer-based psychiatry history system. Archives of General Psychiatry, 1971, 25, 570-572.

Mayne, J. G., Wersel, W., \& Sholtz, P. H. Toward automating the medical history. Mayo Clinic Proceedings, 1968, 43, 1-25.

MeEhl, P. E. Clinical versus statistical prediction. Minneapolis: University of Minnesota Press, 1954.

Overton, W. G., \& Scotr, K. G. Automated and manual intelligence testing: Data on parallel forms of the Peabody Picture Vocabulary Test. American Journal of Mental Deficiency, 1972, 76, 639-643.

Paitich, D. Computers in behavioral science: $A$ comprehensive automated psychological examination and report (CAPER). Behavioral Science, 1973, 108, 131-136.

Peck, R. F., Menaker, S., \& Veldman, D. J. Computer analysis of sentence completion data. American Psychologist, 1966, 21, 678.

Pope, A. T., \& Gensten, C. D. Computer automation of biofeedback training. Behavior Research Methods \& Instrumentation, 1977, 9, 164-168.

Reich, T., Robins, L. N., Woodruft, R. A., Jr., Taibleson, M., Rich, C., \& Cunningham, L. Computer-assisted derivation of a screening interview for alcoholism. Archives of General Psychiatry, 1975, 32, 847-852.

Rosenberg, M., \& Glueck, B. C. Further developments in automation of behavioral observations on hospitalized psychiatric patients. Comprehensive Psychiatry, 1967, 8, 468-475.

Rosenthat, R. On the social psychology of a psychology experiment: Experimenters' hypothesis as unintended determined experimental results. American Scientist, 1963, 51, 268-283.

Sapinkops, R. C. A computer adaptive testing approach to the measurement of personality variables. Dissertation Abstracts International, 1978, 38, 10B, 4993.

Scissons, E. H. Computer administration of the California Psychological Inventory. Measure and Evaluation in Guidance, 1976, 9, 22-25.

Slack, W. V., Hicks, G. P., Reed, C. Z., \& VanCuha, L. J. A computer based medical history system. New England Journal of Medicine, 1966, 274, 194-198.

Slack, W. V., \& Slack, C. W. Talking to a computer about emotional problems: A comparative study. Psychotherapy: Theory, Research and Practice, 1977, 14, 156-164.

Sletten, 1. W., Altman, H., Evenson, R. C., \& Cho, D. W.
Computer assignment of psychotropic drugs. American Journal of Psychiatry, 1973, 130, 595-598.

Sletten, I. W., Ernhard, C. B., \& Ulett, G. A. Automated mental status examination: Development, use and reliability. Comprehensive Psychiatry, 1970, 11, 315-327.

Sletten, I. W., Schuff, S., Altman, H., \& Uletr, G. A statewide computerized psychiatric system: Demographic, diagnostic and mental status data. International Journal of Social Psychiatry, 1972, 108, 30-40.

Sletten, I. W., Ulett, G., Altman, H., \& Sundland, D. The Missouri standard system of psychiatry (SSOP): Computer generated diagnosis. Archives of General Psychiatry, 1970, 23, 73-79.

Space, L. G. A console for the interactive on-line administration of psychological tests. Behavior Research Methods \& Instrumentation, 1975, 7, 191-193.

Space, L. G., \& Huntzinger, R. S. A microprocessor-based psychopathology laboratory: III. Hardware. Behavior Research Methods \& Instrumentation, 1979, 11, 247-252.

Spitzer, R. L., Endicott, J., Cohen, J., \& Fleiss, J. L. Constraints on the validity of computer diagnosis. Archives of General Psychiatry, 1974, 31, 197-203.

Stead, W. W., Heyman, A., Thompson, H. K., \& Hammond, W. E. Computer-assisted interview of patients with functional headache. Archives of Internal Medicine, 1972, 129, 950-955.

Stroebel, C. F., \& Glueck, B. C. Computer derived global judgment psychiatry. American Journal of Psychiatry, 1970, 126, $1057-1066$.

Swenson, W. M., Rome, H. P., Pearson, J. S., \& Brannick, T. L. A total automatic psychological test. Journal of the American Medical Association, 1965, 191, 925-927.

Tucken, G. J., \& Rosenberg, S. D. Computer analysis of schizophrenic speech: An example of computer usage in the study of psychopathologic processes. In J. B. Sidowski, J. H. Johnson, \& T. A. Williams (Eds.), Technology in mental health care delivery systems. Norwood, N.J: Ablex, 1980.

Warner, H. R., Ruthentord, B. D., \& Hautchens, B. A sequential Bayesian approach to history taking and diagnosis. Computers and Biomedical Research, 1972, 5, 256-262.

WEBB, J. T. Validity and utility of computer produced MMPI reports with Veterans Administration psychiatric population. Proceedings of the Annual Convention of the American Psychological Association, 1970, 5, 541-542.

Webb, J. T., Miller, M. L., \& Fowler, R. D. Extending professional time: A computerized MMPI interpretation service. Journal of Clinical Psychology, 1970, 26, 210-214. 